\title{
Two-Step Optimization of Envelope Design for the Reduction of Building Energy Demand
}

\author{
Alberto Barbaresi ${ }^{1}$, Giulia Menichetti ${ }^{2}$, Enrica Santolini ${ }^{1}$, Daniele Torreggiani ${ }^{1}$, Patrizia Tassinari ${ }^{1}$ \\ ${ }^{1}$ Department of Agricultural and Food Sciences, University of Bologna, Italy \\ ${ }^{2}$ Department of Physics, Northeastern University, Boston (USA)
}

\begin{abstract}
The path towards nearly-Zero Energy Buildings has enforced stricter constraints in construction design while promoting the investigation of new architectural solutions, in residential and producing sectors. Energy simulations, integrated with machine learning, helps academics and professionals to investigate novel strategies for energy saving.

We present here a 2-step methodology based on genetic algorithms, aiming to reduce the energy consumption for indoor heating and cooling, while identifying the most suitable commercial solutions for external wall and roof constructions. We compare it with a 1-step optimization algorithm with the goal to determine pros and cons of both methodologies. Even if the two methodologies are comparable in terms of energy reduction, the 2-step algorithm is less computationally expensive and finds several plausible architectural solutions, with equivalent energy profile.
\end{abstract}

\section{Introduction}

The building industry is facing a challenging period between impelling needs and new opportunities.

The growing warnings on climate changes has highlighted the depletion of non-renewable resources concerning the construction sector. Since the Kyoto's protocol (United Nations, 1998), national laws and regulations have followed a renewed environmental policy oriented to reduce the use of natural resources. Nations pursue this goal imposing stricter limits to building energy consumption for heating and cooling needs, that, represents the $40 \%$ of total energy consumption and the $36 \%$ of $\mathrm{CO}_{2}$ emissions for the European Union (European Commission, 2018).

To reduce the energy consumption we need to improve the building technology by optimizing the energy exploitation, both for new constructions and existing ones. With this purpose, the European Parliament developed the concept of $n Z E B$ (nearly ZeroEnergy Building), a reference building that requires very low amount of energy, and that should be covered mainly by renewable-energy sources, including on-site and nearby productions (European Parliament and Council, 2010).

Even if the aim of $n Z E B$ is straightforward, the lack of consistent reference indicators for the building sec- tor allowed each European Union Members to define them independently. Different local needs worked against an unified calculation framework valid in the whole European Union territory. Despite the unavoidable differences in the methodologies, all the regulations must consider the building as a whole, differently from some old and current regulations, such as Italian energy saving law (Presidenza del Consiglio dei Ministri, 2013), that require the compliance of each single element.

These forthcoming changes demand from firms, professionals, academics and designers, new materials and architectural solutions in agreement with the nZEB criteria.

Remarkably, besides the traditional insulation material, firms now investigate high-technology and nature-based new materials for the building envelope, increasing the possibilities to design and realize lowenergy-consumption buildings (Ahangari and Maerefat, 2019; Lachheb et al., 2019).

Rural buildings are suitable constructions for naturebased material application, mainly applied for food processing and storage buildings. These structures are often not required to meet energy-saving regulation constraints, even though the indoor climate control plays a fundamental role to preserve food safety and improve quality (Mazarrón et al., 2012; De Rosis et al., 2014). Thanks to high incidence in production costs and increased customers' awareness of environmental sustainability issues, energy saving has recently gained increasing attention in farm building design and construction as well, with a particular focus on food - and wine - processing buildings. (Benni et al., 2013; Torreggiani et al., 2014).

In summary, the new energy saving requirements in the building sector are driving to stricter and stricter constraints and at the same time new opportunities in terms of building solutions, from residential to producing buildings.

The appropriate design of the building envelope is a key aspect of energy saving. Remarkably, Fan and Xia (2017) showed that over $50 \%$ of energy consumption in the buildings is related to the heat losses through the shell, so energy efficiency in envelope design becomes a priority. The preliminary energetic assessment of new building solutions is now com- 
monly analyzed by computational simulations (Barbaresi et al., 2014; Ramos Ruiz et al., 2016). For instance, Chen et al. (2019) employed a hybrid generalized pattern search particle swarm optimization (HGPSPSO) and sensitivity analysis to evaluate the effects of the urban contexts and various envelope features to optimize the energy needs and to define accurate guidelines for high rise buildings. With the focus on improvement of existing buildings, Risholt et al. (2013), modelled a house in Norway, by employing passive components and renewable energy resources and evaluating the optimized condition among energy and home quality indicators. With similar intent, Hong et al. (2019) developed a multi-objective methodology through genetic algorithm to optimize the energy design of a library in a university located in Seoul, by considering window type, set point temperature and ventilation to optimize economic, environmental and energetic criteria. In summary, the literature provides multiple examples of energy simulations tailored to optimize single building instances, but lacking easy generalization and adaptability (Longo et al., 2018). The main goal of this work is then to optimize the building envelope to reduce the energy consumption for heating and cooling, while retaining several material solutions for external wall and roof constructions. In the following, we compare our 2-step optimization protocol, based on an initial analysis over the theoretical thermal properties of the building envelope, with a 1-step procedure, dependent on the selection of a given database of construction materials.

\section{Methods}

The present Section describes the hardware, the software and the programs chosen for this work, the casestudy, the simulation parameters, the class of algorithms, the solving procedures defined by the $\mathrm{Au}-$ thors, the database of materials and finally the analyses and indicators used to compare the procedures.

\section{Hardware, software and programs}

The method in this paper is based on the analyses of energy simulations' results, achieved and analyzed by two main programs: EnergyPlus 8.1 (U.S. Department of Energy, 2018) and MatLab 2017b (Mathworks, 2017). The first is a program for dynamic energy building simulations widely used in scientific literature (Longo et al., 2018), the second is a multiparadigm numerical computing environment developed to solve iterative analyses. Several works take advantage of those programs and of their interactivity (Torreggiani et al., 2017; Escandón et al., 2019). More in detail:

- MatLab is used to code and calculate the optimization procedure, create EnergyPlus models, launch EP simulations (with a comprehensive EnegyPlus wether file), run the optimization al-

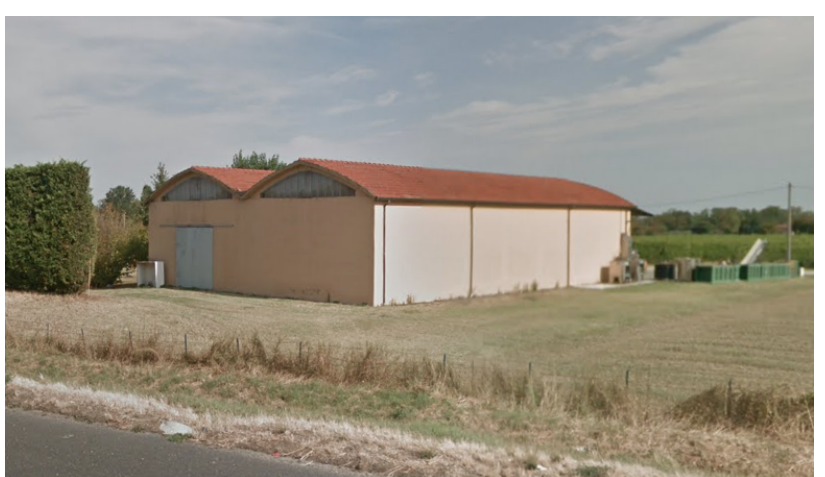

Figure 1: The case-study building. South view

gorithm and performs the data processing;

- EnergyPlus is the dynamic energy simulation engine.

Both these programs are among the most reliable in their application domain, thus they ensure high accuracy of the results. Summing up, EnergyPlus models can be managed, and simulations launched, directly from MatLab environment, allowing simple managements of iterative procedures such as genetic algorithms. Other software used in this work are OpenStudio, AutoCad, Trimble SketchUp and text editors for the realization of the first model of case study building, called hereinafter BaseModel. The computer used in this work is provided with Intel ${ }^{\circledR}$ Xeon ${ }^{\circledR} \mathrm{CPU}, 3.06 \mathrm{GHz}, 6.00 \mathrm{~GB}$ RAM, Windows 10 Pro.

\section{Case study}

The case study chosen for this work is a wine-making and storage building located in the central part of Italy, specifically in Bologna countryside. The building, shown in the Figure 1, is $30 \mathrm{~m}$ long and $20 \mathrm{~m}$ wide, the height varies between 5 and $7 \mathrm{~m}$. The main axis is $32^{\circ} \mathrm{NE}$ oriented. Internally, it is virtually divided in two parts by a row of pillars located in the centre, along the longitudinal axis. One part is dedicated to wine-making (non-conditioned area), the other is used as wine storage area. The latter is conditioned; the analyses in this work will refer to this volume only.

This building was chosen for two main reasons:

- Simulation reliability: the building indoor conditions, ground temperatures and the meteorological data were recorded for 2 years. Collected data allowed to realize, calibrate and validate an EnergyPlus thermal model for software simulations (Barbaresi et al., 2017; Tinti et al., 2015);

- Specificity reduction: the building geometry and thermal needs are simple, precisely the storage area thermostat requires the same temperature range $\left(12^{\circ} \mathrm{C}-18^{\circ} \mathrm{C}\right)$ throughout the whole year (Marescalchi, 1965; Vogt, 1971). This solution reduces the singular effects due to specificity of building shape or thermal needs during the simulation process, easing the comparison between 


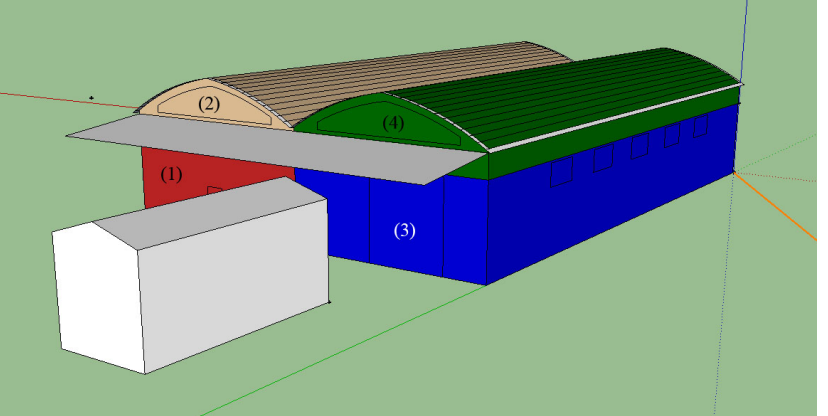

Figure 2: The case-study model. North view. (1) wine-making area, (3) wine storage area, (1) and (4) roof areas.

the two approaches, aim of this work.

The building is modelled in EnergyPlus as a fourthermal-zone construction as shown in the Figure 2. Beside the wine-making area and storage, other two volumes under the roofs were modelled, since these parts of the buildings exhibit different thermal behaviour of the underlying volumes, as analyzed in Barbaresi et al. (2017).

The stored wine was modelled as thermal mass objects with same surface and volume of wine bottles and with wine thermal properties as reported in Boulton et al. (1998).

\section{Simulation inputs}

The EnergyPlus BaseModel was created on the basis of the validated model. A few input parameters of the BaseModel will be changed creating new models whose final energy demand will be used to evaluate their energy efficiency. All other input parameters are considered constant.

- (main) constant parameters: building shape and dimensions, thermostat setting, weather conditions (.epw file), ground temperature, floor slab;

- variable parameters: external walls, roofs, building orientation (degree), windows U-value $\left(W / m^{2} K\right)$ and air infiltration (air changes per hour).

External walls and roof are input in two different ways according to the chosen procedure, as better specified in the following Sections. The weather file was created gathering on-site weather data for more than two years. For this work, data from 01/01/2013 until $31 / 12 / 2013$ were used. EnergyPlus program, among several outputs, returns the energy demand $(k W h)$ of the wine storage area, the only output considered in this work.

Matlab codes were created to generate building models starting from BaseModel, to launch the simulations in EnergyPlus environment, to run the solving algorithms and to modify the models according to algorithm results. Finally, it was used for the result analyses as well.

\section{Genetic Algorithms}

Genetic algorithms (GAs) are solving procedures based on the Darwinian evolution theory and related natural selection (Holland, 1975). They are designed and developed to optimize and generate high-quality solutions starting from an initial population (randomly created) and, using operators such as mutation, crossover, selection and generations, GAs create more performing individuals driven by a specific criterion defined by a fitting equation.

More in detail, GA starts creating a population of $n$ individuals (energy models) called first generation. The individuals differ for specific characteristics called genes (simulation variable parameters). Values of genes are randomly attributed. GA randomly chooses two sets of $t$ individuals and assesses their individual performances (energy need) according to a fitting equation (minimum energy need). The best individuals of the two sets have higher probability to be selected as parents to create a new individual for the following generation. The new individual is created using the genes of the parents. For each gene of the new individual, a mutation can occur with a probability of $m$; if a gene mutation occurs, that gene is substituted with a randomly chosen new gene. This operation is repeated $n$ times in order to complete the next generation. This procedure is intended to create more and more efficient individuals and will repeated until a fixed number of generation $g$ is reached or a specific individual performance achieved.

For both the solving approaches used in this work, starting from the BaseModel, several different models of the building are created assembling an initial population, called Generation 1. The models differ for the variable parameters - as defined in the previous Section - randomly assigned in the first Generation. The algorithm chooses the most (energy saving) solutions for the creation of a new population of models (reproduction), according to a fitting equation that identifies the lowest energy consuming models.

\section{Solving approaches}

The thermal performance of a building is strictly dependent on its envelope, in particular on external walls and roof (Torreggiani et al., 2017). According to EnergyPlus input phase, walls and roofs are inserted as constructions (layers of materials). For each material, the user enters the main thermal properties, such as thermal conductivity, specific heat and density. The program automatically calculates the global thermal characteristics of the constructions. The main ones are the thermal transmittance, the superficial mass, the thermal lag, the attenuation coefficient etc. These values are used in the simulations to calculate the thermal behaviour of the building. The present work proposes two different input phase for external walls and roof:

- 1-Phase procedure: the code generates building 
constructions as combination of 3 materials with their thickness, picking materials from a given database. These constructions are directly inserted in EnergyPlus models. At the end of the solving algorithm, simulations return the most energy performing model that contains walls and roof as 3-layers (i.e. 3-materials) constructions.

- 2-Phase procedure: the generating code creates constructions as theoretical values (Phase 1) inputting a 20-cm-thick fictitious material and its thermal characteristics: conductivity, density and specific heat. At the end of the solving algorithm, simulations return the most energy performing model that contains theoretical values of walls and roof only (no material is considered in this phase). A second genetic algorithm (Phase 2) creates 3-materials constructions - picking from a material database - that best fit the theoretical values identified in the Phase 1.

The two approaches have the same aim: finding the most energy saving solution for the case-study building. At the end of both procedures, the final solutions contain the construction materials to be used as external walls and roof. While the first approach inserts in EnergyPlus the materials taken form a database returning wall and roof materials at the end of energy simulations, the second approach splits the problem in two phases: the first run energy simulations with construction theoretical values only, than the second identifies the proper constructions (materials).

\section{Material database}

A research in the building market supply and in the scientific literature (Sassoni et al., 2014; Asdrubali et al., 2017; Bourdot et al., 2017; Lamrani et al., 2017) allowed to create a database of materials containing 94 materials with related thermal properties. For each material minimum and maximum thickness are reported. Summing up, each database line contains:

- code and extend name;

- main thermal properties: thermal conductivity, density, specific heat;

- secondary properties: thermal, solar and visible absorbency;

- minimum and maximum thickness and increment step for model constructions.

The included materials have mineral (34), vegetable (37), synthetic (2), composite (20) and animal (1) origin. Both procedure refer to this database to create constructions: the 1-Phase procedure since the creation of the initial population, the 2-Phase procedure in the second phase only.

\section{Analyses and indicators}

The main aim of this work is to compare the two proposed approaches to identify the most effective one.
The approaches are evaluated according to different indicators:

- Final energy: the best solutions (models) achieved by the two approaches will be compared in terms of final energy need $(k W h)$;

- Initial space of thermal characteristics: for the energy simulation, constructions are combinations of thermal characteristics; this indicator globally compares the initial walls and roof (belonging to the Generation 1) as combination of thermal resistance $\left(m^{2} K / k W h\right)$, superficial mass $\left(\mathrm{kg} / \mathrm{m}^{2}\right)$ and thermal lag $(h)$;

- Material presence: A limited number of insulation materials are usually used to build walls and roofs, related to the construction market supply. Finding constructions with same thermal characteristics made by different materials, can give more opportunities to professionals and firms involved in the construction sector. This indicator evaluates the probability of each material to be present in the constructions of the most performing solutions achieved by the 2 approaches.

\section{Simulation constraints}

To make comparable the results achieved by the two approaches, a few constraints were imposed equal to the both procedures:

- maximum thickness of constructions;

- minimum thermal transmittance of constructions;

- GAs' parameters (population, generation, mutation probability, etc.).

\section{Results}

In this Section, the results of the two approaches are compared, evaluated and discussed, according to the indicators as defined in the previous Section.

Preliminary tests allowed to define some constraints to apply to both procedures, as shown in the Table

1. Hence each simulation has 100-individual popu-

Table 1: Limits and constraints applied to both procedures's parameters

\begin{tabular}{lrl} 
Parameters & Value & Unit \\
\hline Population & 100 & \\
Generations & 25 & \\
Mutation coefficient & 0.1 & \\
Repetition & 4 & \\
Construction thickness & 35.6 & $\mathrm{~cm}$ \\
Construction th. transmittance & 0.194 & $\mathrm{~W} / \mathrm{m}^{2} \mathrm{~K}$ \\
\hline
\end{tabular}

lations (energy models), runs for 25 generations; 0.1 mutation coefficient was applied. To improve the results' precision, each procedure is repeated four times. The Phase 2, in the 2-Phase procedure, works with 1000-individual population (constructions), performs 
for 50 generations, with 0.1 mutation coefficient. Before analysing the final results, the calculation time was been monitored; the first procedure, 1-Phase, complete every energy algorithm simulation in the average time of 1376 minutes, the second, 2-Phase, in 1305. It is visible the two approaches takes almost the same time (2-Phase $5 \%$ faster); though it should be recalled that the 2-Phase needs a second algorithm (second phase) that averagely takes 5 minutes and should be run twice: one for identify the wall construction and one for roof construction, therefore the final time to complete the procedure is estimated in $1315,4.5 \%$ faster than 1-Phase procedure. Supposing the EnergyPlus simulations account the same time, independently of the procedure, the difference should be generated in the reproduction phase performed by Matlab. Further studies will investigate this guess.

\section{Final Energy}

The first evaluated parameter is the final energy achieved by the procedures. Specifically the most energy saving models, identified by the two procedure, are compared.

As previously said, the algorithms were run four times for each procedure. As visible in the Table 2, the results returned by the two performances, exhibit negligible differences (less than $20 \mathrm{kWh}$ on the minimum, corresponding to $0.1 \%$ ).

Table 2: The most performing models in terms of energy need performed by the two procedures

Most energy saving model

\begin{tabular}{lrrr}
\hline$\bullet$ & $\begin{array}{r}\text { minimum } \\
k W h\end{array}$ & $\begin{array}{r}\text { average } \\
k W h\end{array}$ & $\begin{array}{r}\text { st. dev. } \\
k W h\end{array}$ \\
\hline 1-Phase & 16904 & 16935 & 43 \\
2-Phase & 16921 & 16967 & 44
\end{tabular}

Despite the similarity in the best model, differences can be found observing the last generations. The Figure 3 exhibits the cumulative distribution functions of the energies demands returned by the models belonging to the last generations of both procedures (repeated for four times). The graph shows that the 2-Phase procedure (red line) globally produced more performing solutions (numerical values are reported in the Table 3): as example, half of the models of 2Phase procedure are under $17133 \mathrm{kWh}$ of energy demand that is $1.3 \%$ higher than the minimum (see Table 2), on the other side, half of the energy demands of 1-Phase procedure are as high as $19839 \mathrm{kWh}$, the $117.4 \%$ of the most performing model.

\section{Initial space of thermal characteristics}

As explained in the previous Section, the initial population is randomly created, therefore a high number of non-performing solutions are expected in the first generation.

Even though the procedure creates walls and roof of

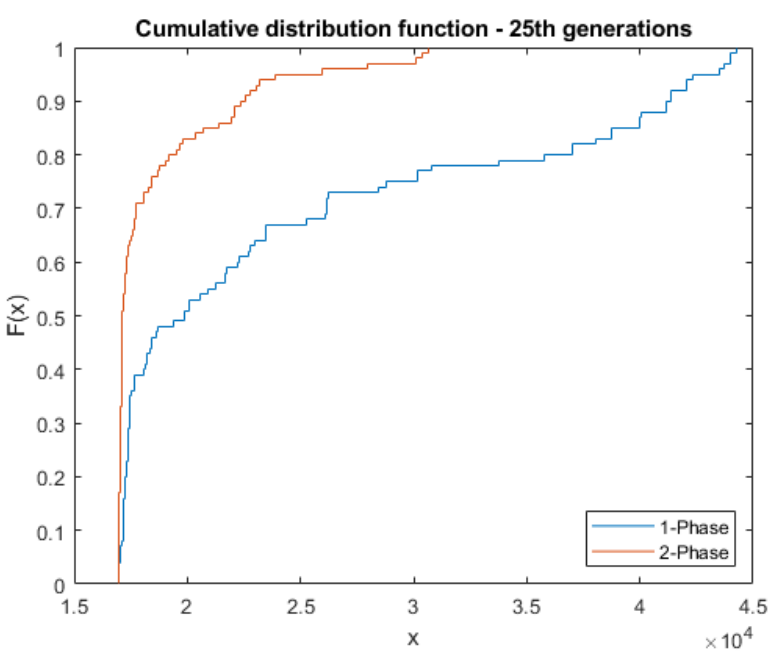

Figure 3: The cumulative distribution functions. Values in $x$-axis are expressed in $k W h$

Table 3: Last generation energy demand values (kWh)

Energy quantiles - last generation

\begin{tabular}{lrrrr}
\hline Quantiles & 0.3 & 0.5 & 0.7 & 0.9 \\
\hline 1-Phase & 17429 & 19839 & 26153 & 41264 \\
2-Phase & 17027 & 17133 & 17742 & 22479
\end{tabular}

initial populations in different ways, their constructions can be compared using their global thermal properties. The Figures 4 and 5 locate in the space every construction according to 3 coordinates: thermal resistance $\left(\mathrm{m}^{2} \mathrm{~K} / \mathrm{W}\right)$, superficial mass $\left(\mathrm{kg} / \mathrm{m}^{2}\right)$ and thermal lag $(h)$.

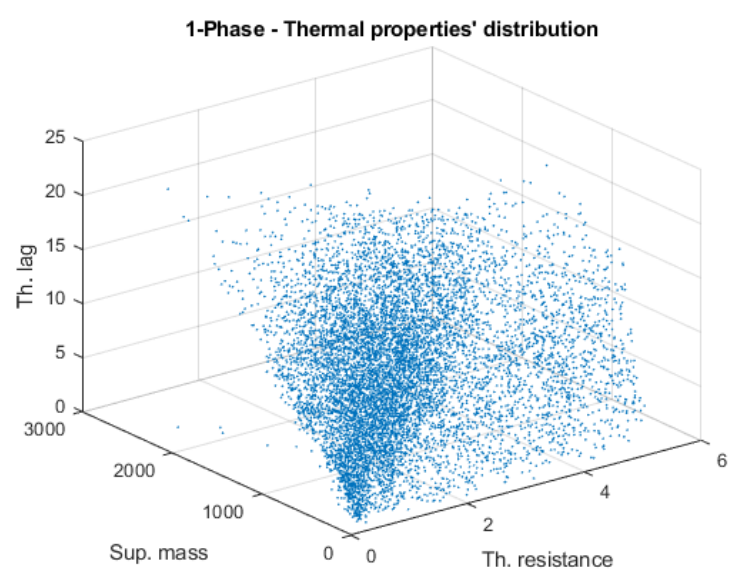

Figure 4: Distribution of thermal properties of constructions in 1-Phase procedure

For this specific analysis, 50 initial populations were generated allowing the location of 10.000 construction for each procedure. It is clear the 2-Phase procedure has a more uniform distribution, entailing that 2-Phase procedure is able to investigate the thermalproperty-construction space in a deeper detail. This result can be explained considering the input phase. 


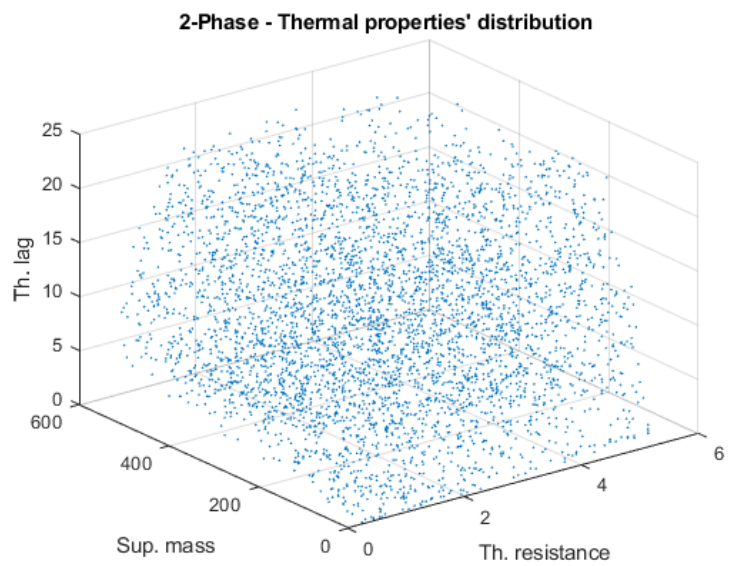

Figure 5: Distribution of thermal properties of constructions in 2-Phase procedure

In 2-Phase procedure the three thermal characteristics are randomly and independently generated, on the contrary, in the 1-Phase procedure they derive from measured material characteristics that we can assume to be non-independent.

\section{Material presence probability}

As previously explained, both the procedures refer to the same database that contains 94 materials. For each procedure the 70 most performing solutions were analysed; considering that each of the 70 chosen model contains 2 constructions (walls and roof), and each construction contains 3 materials, this analysis considers 420 layer (materials) for each procedure.

The Figures 6 and 7 reports the graphs related to the material presence in the most energy performing solutions. In other words, they show the probability of each material to be present in the most performing constructions.

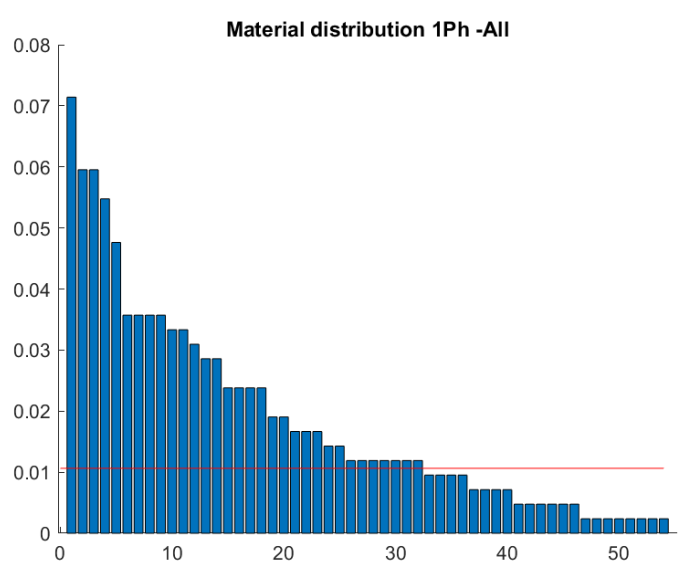

Figure 6: Appearance probability of a materials in 1Phase constructions

The $y$-axis reports the probability, the $x$-axis the number of materials belonging to the database. These materials are sorted from the highest probability ma-

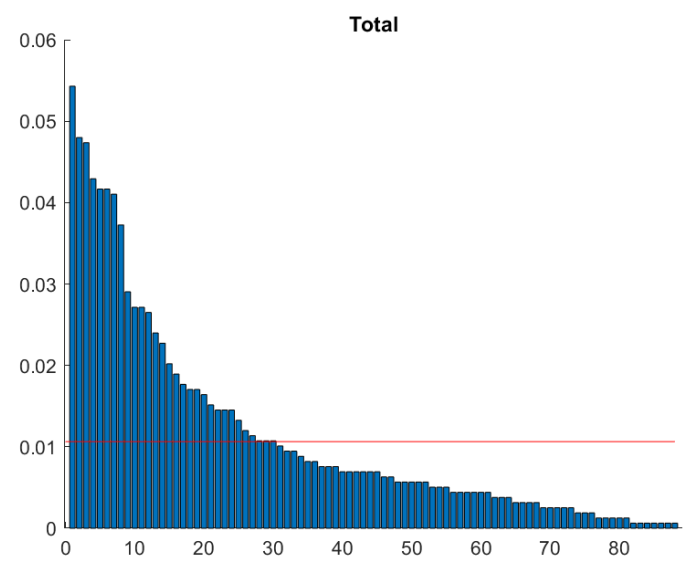

Figure 7: Appearance probability of materials in 2Phase constructions

terial to the lowest (no code nor name of materials is described in the graphs for readability reasons). The red line represents the probability of each material to be in the constructions if randomly chosen.

The $x$-axes, reports that 54 materials $(57 \%$ of the database) are present in the most performing solutions of 1-Phase procedure (see 6), versus 88 (94\%) in the 2-Phase (see 7), highlighting the 2-Phase procedure better investigates the given database. The top five materials in terms of probability are shown in the Table 4 (1-Phase procedure) and Table 5 (2-Phase). Form left to right, columns describe the rank, the database code, the presence probability, and finally material description.

Table 4: Rank of most used materials in the best energy models (1-Phase)

\begin{tabular}{rrrl}
\hline \multicolumn{4}{c}{ 1-Phase material probability } \\
$\#$ & Code & Probability & Material \\
\hline 1 & C02 & 0.0714 & Polyurethan panels \\
2 & B14 & 0.0595 & Coconut fibre \\
3 & E01 & 0.0595 & Sheep wool \\
4 & A30 & 0.0548 & Stone masonry \\
5 & A17 & 0.0478 & Cement
\end{tabular}

Table 5: Rank of most used materials in the best energy models (2-Phase)

\begin{tabular}{rcrl}
\hline \multicolumn{4}{c}{ 2-Phase material probability } \\
$\#$ & Code & Probability & Material \\
\hline 1 & B18 & 0.0543 & Cork \\
2 & B14 & 0.0480 & Coconut fibre \\
3 & A05 & 0.0479 & Glass wool \\
4 & B15 & 0.0474 & Hemp hurd \\
5 & B01 & 0.0417 & LD wood fiberboard
\end{tabular}

\section{Possible applications}

As example, we considered the best models achieved by the 2 procedures and we analyzed the returned wall constructions. The Table 6 shows the wall construction (3 layers and related thickness) for 1-Phase 
procedure. Results of the 2-Phase procedure are summarized in the Table 7 that shows that the secondphase GA, returned 2 suitable solutions. Another remarkable outcome, in fact, is that the 2-Phase can return more than one construction for the same model, and considering the computational velocity, this phase can be repeated as long as the solution can be considered satisfactory.

Table 6: Wall construction in the best model of 1Phase procedure

Best model wall (1-Phase)

\begin{tabular}{crl} 
Code & Thickness $(m)$ & Name \\
\hline D07 & 0.150 & Fibre reinforced mud brick \\
E01 & 0.150 & Sheep wool \\
A30 & 0.035 & Stone masonry
\end{tabular}

Table 7: Wall construction in the best model of 2Phase procedure

Solution 1

Best model wall (2-Phase)

\begin{tabular}{|c|c|c|}
\hline Code & Thickness $(m)$ & Name \\
\hline D07 & 0.070 & Fibre reinforced mud brick \\
\hline B06 & 0.060 & Wood particleboard HD \\
\hline $\mathrm{C} 02$ & 0.011 & Polyurethane panels \\
\hline \multicolumn{3}{|c|}{ Solution 2} \\
\hline Code & Thickness $(m)$ & Name \\
\hline D07 & 0.100 & Fibre reinforced mud brick \\
\hline B36 & 0.140 & Cellulose insulation \\
\hline B37 & 0.050 & Recycled paper panels \\
\hline
\end{tabular}

\section{Conclusions}

The present work compares two GA-based procedures designed to find the most energy saving solutions in a case-study building. The two procedures differs for walls and roof definition. The first (1-Phase) creates constructions directly picking materials from a database, the second (2-Phase) works with theoretical values and, in a second phase, associates materials to most performing solutions.

Results show 2-Phase procedure is slightly faster (4\%), no remarkable differences are evident in the most most energy saving solution (16900 kWh), the 2-Phase last generation returns more energy efficient solutions (50\% of the 2-Phase solutions are below the $102 \%$ of best-model energy need, while the $50 \%$ of the 1-Phase solutions are below the $117 \%$ of best-model energy need).

Other considerations can be made on the two procedures comparison. In their final result, both the procedure accuracies are affected by the material database reliability, but while the 1-Phase uses the database since the first step, the 2-Phase resort to the database only in the second phase, entailing the first phase is not affected by the database precision. Moreover, considering the speed of the second phase,
(10 minutes for each model), the outputs of the first phase can be used with different databases, increasing the variability of final constructions.

Summing up, the 2-Phase procedure proved to be as effective as the 1-Phase procedure to find the most energy saving solution, but exhibits better performance in terms of calculation velocity, number of lowconsumption solutions and constructions' variability. Further developments will investigate different building parameters.

\section{References}

Ahangari, M. and M. Maerefat (2019). An innovative PCM system for thermal comfort improvement and energy demand reduction in building under different climate conditions. Sustainable Cities and Society 44, 120-129.

Asdrubali, F., B. Ferracuti, L. Lombardi, C. Guattari, L. Evangelisti, and G. Grazieschi (2017, mar). A review of structural, thermo-physical, acoustical, and environmental properties of wooden materials for building applications. Building and Environment 114, 307-332.

Barbaresi, A., F. Dallacasa, D. Torreggiani, and P. Tassinari (2017). Retrofit interventions in nonconditioned rooms: calibration of an assessment method on a farm winery. Journal of Building Performance Simulation 10(January), 91-104.

Barbaresi, A., D. Torreggiani, S. Benni, and P. Tassinari (2014, jun). Underground cellar thermal simulation: Definition of a method for modelling performance assessment based on experimental calibration. Energy and Buildings 76, 363-372.

Benni, S., D. Torreggiani, A. Barbaresi, and P. Tassinari (2013, dec). Thermal Performance Assessment for Energy-Efficient Design of Farm Wineries. Transactions of the ASABE 56(1965), 1483-1491.

Boulton, R. B., V. L. Singleton, L. F. Bisson, and R. E. Kunkee (1998). Principles and practices of winemaking. New York: Springer.

Bourdot, A., T. Moussa, A. Gacoin, C. Maalouf, P. Vazquez, C. Thomachot-Schneider, C. Bliard, A. Merabtine, M. Lachi, O. Douzane, H. Karaky, and G. Polidori (2017). Characterization of a hemp-based agro-material: Influence of starch ratio and hemp shive size on physical, mechanical, and hygrothermal properties. Energy and Buildings 153, 501-512.

Chen, X., H. Yang, and J. Peng (2019). Energy optimization of high-rise commercial buildings integrated with photovoltaic facades in urban context. Energy 172, 1-17. 
De Rosis, A., A. Barbaresi, D. Torreggiani, S. Benni, and P. Tassinari (2014, nov). Numerical simulations of the airflows in a wine-aging room: A lattice Boltzmann-Immersed Boundary study. Computers and Electronics in Agriculture 109, 261-270.

Escandón, R., F. Ascione, N. Bianco, G. Mauro, R. Suárez, and J. Sendra (2019). Thermal comfort prediction in a building category: Artificial neural network generation from calibrated models for a social housing stock in southern Europe. Applied Thermal Engineering 150, 492-505.

European Commission (2018). Energy Efficiency Buildings.

(2010). Directive 2010/31/EU of the European parliament and of the council of 19 May 2010 on the energy performance of buildings.

Fan, Y. and X. Xia (2017). A multi-objective optimization model for energy-efficiency building envelope retrofitting plan with rooftop PV system installation and maintenance. Applied Energy 189, 327-335.

Holland, J. H. (1975). Adaptation in natural and artificial systems. Cambridge: MIT Press.

Hong, T., J. Kim, and M. Lee (2019). A multiobjective optimization model for determining the building design and occupant behaviors based on energy, economic, and environmental performance. Energy 174, 823-834.

Lachheb, A., A. Allouhi, M. El Marhoune, R. Saadani, T. Kousksou, A. Jamil, M. Rahmoune, and O. Oussouaddi (2019). Thermal insulation improvement in construction materials by adding spent coffee grounds: An experimental and simulation study. Journal of Cleaner Production 209, 1411-1419.

Lamrani, M., N. Laaroussi, A. Khabbazi, M. Khalfaoui, M. Garoum, and A. Feiz (2017). Experimental study of thermal properties of a new ecological building material based on peanut shells and plaster. Case Studies in Construction Materials 7(July), 294-304.

Longo, S., F. Montana, and E. R. Sanseverino (2018). A review on optimization and cost-optimal methodologies in low-energy buildings design and environmental considerations. Sustainable Cities and Society 45(November 2018), 87-104.

Marescalchi, C. (1965). Manuale dell enologo (Winemaking Manual). Casale Monferrato: Fratelli Marescalchi.

Mathworks (2017). Matlab R2017b.
Mazarrón, F., J. Cid-Falceto, and I. Cañas Guerrero (2012, feb). An assessment of using ground thermal inertia as passive thermal technique in the wine industry around the world. Applied Thermal Engineering 33-34, 54-61.

Presidenza del Consiglio dei Ministri (2013). Disposizioni urgenti per il recepimento della Direttiva 2010/31/UE del Parlamento europeo e del Consiglio del 19 maggio 2010, sulla prestazione energetica nell'edilizia per la definizione delle procedure d'infrazione avviate dalla Commissione europea, non.

Ramos Ruiz, G., C. Fernández Bandera, T. GómezAcebo Temes, and A. Sánchez-Ostiz Gutierrez (2016). Genetic algorithm for building envelope calibration. Applied Energy 168, 691-705.

Risholt, B., B. Time, and A. G. Hestnes (2013). Sustainability assessment of nearly zero energy renovation of dwellings based on energy, economy and home quality indicators. Energy and Buildings 60, 217-224.

Sassoni, E., S. Manzi, A. Motori, M. Montecchi, and M. Canti (2014). Novel sustainable hemp-based composites for application in the building industry: Physical, thermal and mechanical characterization. Energy and Buildings 77, 219-226.

Tinti, F., A. Barbaresi, S. Benni, D. Torreggiani, R. Bruno, and P. Tassinari (2015). Experimental Analysis of Thermal Interaction Between Wine Cellar and Underground. Energy and Buildings 104, 275-286.

Torreggiani, D., A. Barbaresi, F. Dallacasa, and P. Tassinari (2017). Effects of different architectural solutions on the thermal behaviour in an unconditioned rural building. The case of an Italian winery. Journal of Agricultural Engineering Under revi.

Torreggiani, D., S. Benni, A. I. Garcia, F. Ayuga, and P. Tassinari (2014, may). Farm Winery Layout Design: Size Analysis of Base Spatial Units in an Italian Study Area. Transactions of the ASABE 57(2), 625-633.

United Nations (1998). Kyoto Protocol to the United Nations Framework Convention on Climate Change.

U.S. Department of Energy (2018). Energy Plus 8.1.

Vogt, E. (1971). Fabricacion de vinos (Winemaking). Zaragoza: Editorial Acribia. 